\section{MEI}

II, vol. 3

$n^{0} 4$

\title{
Análisis de sitios web sobre regalos de empresa posicionados en Google.es
}

\author{
Daniel Marcos Casanova Bono \\ Universitat Politècnica de Valencia
}

\section{Resumen}

Los regalos de empresa constituyen uno de los sectores comerciales que recurren a la venta online. El posicionamiento de los sitios web de estas empresas es fundamental para aumentar su visibilidad, pero no conlleva una calidad pareja en el resto de aspectos sobre su diseño y gestión. A partir de una búsqueda en Google.es realizada en febrero de 2011, se han elegido 20 sitios web según su orden de relevancia. Los criterios de análisis elegidos están basados en técnicas de arquitectura de la información, usabilidad y marketing online. Los resultados del análisis se agrupan en un modelo simplificado de una matriz DAFO. El estudio del análisis muestra un retraso generalizado respecto a las posibilidades actuales de un sitio web de carácter comercial. Existe un margen de mejora que puede ser aprovechado como oportunidad por las empresas del sector. Para ello es recomendable la asistencia de profesionales con competencias en las disciplinas mencionadas.

\section{Palabras clave}

Regalos de empresa, Sitios web, Arquitectura de la información, Usabilidad, Marketing online, España.

Analysis of websites on corporate gifts positioned on Google.es

\begin{abstract}
Business gifts are one of the commercial sectors that appeal to online sales. The positioning of the websites of these companies is essential to increase its visibility, but it does not imply a similar quality in other aspects of their design and management. From a search done on Google.es in February 2011, 20 websites have been chosen in order of relevance. The selected criteria analysis' techniques are based on information architecture, usability and online marketing. The results of the analysis are showed by means of a simplified SWOT matrix model. The study shows a general delay analysis regarding the possible effects of a commercial website. There is margin improvement that can be exploited as an opportunity for the companies. For that reason, we recommend the assistance of professional competence in the mentioned disciplines.
\end{abstract}

\section{Keywords}

Corporate gifts, Websites, Information arquitectura, Usability, Online marketing, Spain.

\section{Introducción}

El presente artículo tiene como objetivo realizar un análisis de los sitios web dedicados al comercio de regalos navideños ${ }^{1}$, con el fin de identificar aquellas características que permitan aumentar su visibilidad y la venta de productos. Para ello se realiza una revisión de los criterios de análisis de sitios web, presentes en una selección de artículos académicos pertenecientes al ámbito del marketing online. 
En segundo lugar se realiza una búsqueda en Google de las 20 empresas mejor posicionadas. A continuación, se analizan una serie de indicadores como la presentación de los productos, el diseño del sitio web, la identificación y ubicación de la empresa y los avisos legales. Con estos datos se confecciona, en la medida de lo posible, un análisis DAFO por cada sitio web y se realiza una comparación de los distintos resultados.

El artículo comienza exponiendo en el apartado 2 la síntesis de los criterios de análisis en la literatura analizada. En el apartado 3 se explica el proceso de búsqueda de los sitios web en Google y sus resultados. El apartado 4 detalla los criterios de análisis escogidos, dedicándose el apartado 5 a exponer los resultados del análisis. El apartado 6 muestra la discusión sobre dichos resultados y las conclusiones obtenidas.

\section{Criterios de análisis en el ámbito del marketing en Internet}

Los atributos de sitios web presentados a continuación han sido incluidos en los diferentes artículos analizados y sus respectivos autores le han asignado un determinado valor o peso a cada uno de ellos. Sin embargo, en ocasiones se previene que el valor de tales atributos puede no ser concluyente o aplicable a todos los casos.

Además hay que considerar que dichos valores pueden variar debido a la evolución en las prestaciones de los sitios web o al cambio en las tendencias. Por ello, se ha tratado el conjunto de los atributos como una referencia para los criterios de análisis finalmente adoptados, sin considerar los valores asignados a cada uno de ellos.

\subsection{Información sobre los productos}

Contenido presente en el sitio web sobre los productos ofertados: diferenciación de las clases de productos, variedad de los productos, claridad de las descripciones, especificaciones de cada producto, su precio, instrucciones de uso, información de garantía, lista de los productos en promoción, lista de nuevos productos, fotografías pequeñas (thumbnails) y fotografías detalladas, comparación con los precios de los productos en otras tiendas online, comparación de las características de un producto entre diferentes marcas, evaluaciones de calidad realizadas por expertos.

\subsection{Atractivo del sitio web}

Unas de las principales motivaciones de los usuarios de Internet son el recreo y el entretenimiento. Para ello, los ingredientes clave de un sitio web son un diseño atractivo (composición de la página y organización del sitio, presencia de galardones por el diseño), una experiencia multimedia (utilización de sonidos y vídeo, visualización en forma de realidad virtual) y características orientadas al entretenimiento (juegos divertidos).

\subsection{Visibilidad del sitio web}

Comprobable mediante el posicionamiento en los motores de búsqueda y en los directorios web; y mediante las referencias externas al sitio en forma de enlaces. 


\subsection{Facilidad de uso}

Principalmente a través de una navegación intuitiva y sencilla, pero también a través de la utilidad de las funciones de ayuda disponibles: búsqueda por palabras clave, mapa del sitio web, etc.

\subsection{Personalización}

Posibilidad de personalizar un sitio web para adaptarse a usuarios individuales y a su experiencia de compra.

Puede examinarse la flexibilidad de las herramientas de personalización. Algunas de dichas herramientas pueden ser: cuentas personales para los clientes, mostrar las preferencias de compra individuales, sistema de recomendaciones de productos y promociones personalizadas, variedad en los métodos de envío de productos, lista personalizada de anteriores adquisiciones de cara a posibles devoluciones o reparaciones por garantía, acceso a la información de facturación y de envío para agilizar los futuros pedidos, personalización de los productos (especialmente los orientados a estilos de vida como muebles y ropa), elaboración de listas personales de compras y adición de ítems a listas de regalos.

\subsection{Interactividad}

Nivel de interactividad del sitio: contenido estático o dinámico, tiempo de respuesta a una pregunta o petición online, tiempo de carga de las páginas y de los elementos como gráficos, vídeo y audio, posibilidad de realizar comentarios y de que los usuarios aporten retroalimentación.

\subsection{Comunidad}

Grado en el que se fomenta un sentido de comunidad entre los visitantes de un sitio web. Se pueden construir relaciones con segmentos pequeños de clientes, agrupándolos en grupos de interés separados. Puede examinarse el número de personas participando en la comunidad, la frecuencia de participación, el grado de implicación de la empresa en la comunidad.

Las herramientas utilizadas pueden ser foros, servicio de chat y de mensajes instantáneos, etc.

\subsection{Seguridad}

Grado de seguridad de la información privada y financiera relativa a los usuarios. Respecto a la información privada, puede comprobarse los compromisos de la empresa sobre su uso, la posibilidad de ver y editar la información personal, y de controlar su diseminación. A este respecto, existen servicios de auditoria como TRUSTe y Verisign que periódicamente comprueban el cumplimiento de las políticas de privacidad de los sitios web.

Respecto a la financiera, se puede comprobar la seguridad relativa a tarjetas de crédito. En ambos casos puede comprobarse la presencia de logos o símbolos que 
representen el sistema de seguridad adoptado.

\subsection{Mantenimiento del sitio web}

Frecuencia de actualización del sitio en cuanto a su diseño y a su contenido, así como los periodos y frecuencia de inactividad del servidor.

\subsection{Confianza}

Confianza que genera un sitio web en los visitantes. Depende de muchos factores: el conocimiento previo que se tenga de la empresa y de su reputación (branding), el nombre del sitio web, sus afiliaciones, el sistema de pago para las transacciones, la garantía de seguridad en éstas, la comodidad al realizar búsquedas, la provisión de información precisa respecto a la resolución de problemas, las condiciones de venta, las políticas de entrega, de devolución y de sustituciones de los productos, el procesamiento de los pedidos, la indicación de la localización del comerciante, de un diseño del sitio que denote calidad y tecnología y de la frecuencia de actualización del sitio.

\subsection{Proceso de los pedidos online}

Posibilidad de realizar pedidos on line y funcionalidades o informaciones asociadas: variedad de los métodos de pedido (formulario online, e-mail, teléfono, fax), carrito de la compra, indicación de los costes totales antes de enviar la orden de pedido, variedad en los métodos de pago (diferentes tarjetas de crédito, Paypal, cheque, etc.), posibilidad de pago del pedido en el momento de la entrega, posibilidad de solicitar el recibo impreso o en formato digital, confirmación del pedido por e-mail, posibilidad de envío de los productos a casa o a la oficina.

\subsection{Soporte al cliente}

Servicios adicionales de asistencia, información o posventa: diagnóstico online de problemas, posibilidad de realizar consultas en formato electrónico, disponibilidad en vivo de un representante de atención al cliente, dirección de e-mail para la atención al cliente, teléfono gratuito de soporte al cliente, descarga de software necesario o útil para los fines del sitio web.

\subsection{Investigación en marketing}

Publicación de encuestas sobre el sitio web y sobre los productos ofrecidos, así como posibilidad de que los usuarios propongan nuevos productos.

\subsection{Publicidad y promoción}

Cupones electrónicos, tablón de anuncios, concursos y sorteos, anuncios en forma de banner, notificaciones por e-mail de los productos en venta.

\subsection{Logística}

Los siguientes atributos dependen más de la capacidad organizativa de la empresa que de las características del sitio web, pero son igualmente importantes de cara a 
conseguir la satisfacción del cliente: disponibilidad en stock del producto pedido, confirmación por e-mail del envío del pedido, seguimiento del estado de los pedidos y de los envíos, variedad en los métodos de entrega (económico, urgente, etc.), entrega en los términos de tiempo establecidos, cumplimiento de las expectativas respecto al producto pedido y sus características.

\subsection{Integración con la tienda física}

Integración de la tienda virtual con los servicios de la tienda física, en caso de existir. Comprobable a través de servicios como: información sobre los precios de los productos y las promociones en la tienda local más cercana, información online sobre el inventario de la tienda local, posibilidad de devolución de productos en la tienda local, impresión de cupones que se hacen efectivos en la tienda local, indicaciones para el desplazamiento hasta la tienda, recogida de productos en la tienda, reserva de cortesía durante 24 horas sobre un producto de la tienda local.

\subsection{Marketing viral}

El marketing viral explota las redes sociales existentes ${ }^{2}$ alentando a los clientes a compartir información sobre productos con sus amistades, y en general con todos los contactos mediante el efecto boca en boca. Dicho efecto crea el potencial para un crecimiento exponencial de la exposición e influencia del mensaje. La información compartida puede incluir las experiencias y opiniones sobre un producto. Sin embargo, existe la posibilidad de que las campañas virales provoquen efectos negativos, como la percepción de violación de la privacidad.

Una estrategia efectiva de marketing viral puede cumplir uno o más de estos puntos: regala productos o servicios, realiza las transmisiones a otros sin necesidad de esfuerzo, es fácilmente escalable de un tamaño pequeño a uno muy grande, explota motivaciones y comportamientos comunes, utiliza las redes de comunicación existentes, saca provecho de los recursos de otros.

\subsection{Marketing experiencial}

El marketing experiencial es un enfoque para conseguir los objetivos del marketing, que se construye alrededor de una idea base que se pretende transmitir e implica una comunicación en dos sentidos y en tiempo real entre una marca y la audiencia objetivo. Tales comunicaciones normalmente se manifiestan en forma de eventos en vivo en los que el consumidor vive, respira y siente la marca y su personalidad.

Dichos eventos pueden resultar exitosos por igual entre muchas plataformas y tecnologías interactivas que faciliten la comunicación entre consumidores y marcas en tiempo real. Por ejemplo, pueden ser realizadas online a través de un mundo virtual como Second Life.

Las experiencias en vivo de la marca permiten a los consumidores probar el producto, divertirse con él, comerlo, beberlo, tocarlo o presionarlo. No importa qué clase de producto o servicio sea si se pueden imbuir los valores esenciales de la marca en las vidas diarias de la audiencia objetivo a través de interacciones agradables, 
atrayéndolos y dejándoles probar.

Las experiencias en vivo de la marca deberían integrarse con el resto de esfuerzos de marketing, utilizando canales adicionales como publicidad, correo directo, promoción de ventas, patrocinio, relaciones públicas, canales digitales y marketing viral. Dichos canales amplifican el impacto de la idea base.

\subsection{Marketing de guerrilla}

El marketing de guerrilla es una forma de marketing que presenta el mensaje de una marca a los consumidores de una manera totalmente inesperada y atractiva a nivel personal. Les ofrece algo tangible y experiencial, afectándoles de una manera más íntima que el marketing tradicional. Busca que los consumidores miren un producto de manera diferente, resultando en una conexión genuina de éstos con el producto o servicio e infundiendo un cierto grado de lealtad a la marca. Para conseguirlo, el marketing de guerrilla se dirige directamente a los consumidores como individuos, ofreciéndoles una experiencia exclusiva.

Sin embargo, para lograr resultados exitosos se debe innovar constantemente y evitar repetir experiencias que acaben formando parte del estándar. Aunque el marketing de guerrilla puede utilizar medios tradicionales de comunicación como los impresos, la radio o la TV, suele consistir en un marketing a nivel de calle, basado en eventos.

Las razones del éxito de los programas basados en este enfoque de marketing son varias:

- Los programas son únicos, ya que se trata de realizar algo que nunca se ha hecho anteriormente para lograr la máxima conexión con los consumidores.

- Están dirigidos a consumidores específicos y al lugar donde viven, trabajan o se recrean, en los momentos en que serán más receptivos al mensaje.

- Son efectivos en costes, ya que se evalúan los recursos disponibles (financieros, creativos o patentados) y se utilizan para maximizar la calidad del mensaje mientras se mantienen los costes bajos (en este sentido, hay que resaltar que el marketing de guerrilla surgió en el ámbito de pequeñas empresas con presupuesto muy bajo).

Llama la atención de los rumores y del efecto boca en boca, y a menudo de la prensa. Al crearse acontecimientos únicos, una cobertura por parte de la prensa puede aportar una exposición a las masas basándose en un presupuesto para una exposición local. 


\subsection{Social media marketing}

Según Tuten (2008), el social media marketing es una categoría amplia de publicidad on line que utiliza el contexto cultural de las comunidades sociales, incluyendo redes sociales (como YouTube, Myspace y Facebook), mundos virtuales (como Second Life, There y Kaneva), sitios sociales de noticias (como Digg y Del.icio.us) y sitios sociales para compartir opiniones (como Epinions), con la intención de conseguir los objetivos de la marca y de comunicación propuestos.

Los beneficios principales que aporta son: puede alentar la interacción entre consumidores y marcas; puede mejorar las percepciones de la "marca como una persona", y por ello fortalecer su personalidad; puede extender el tiempo de exposición de un mensaje al alentar las interacciones; mejora las oportunidades de la comunicación boca en boca acerca de la marca con otras amistades y gente influyente; y asumiendo que la imagen de marca es agradable y creíble, puede facilitar la interiorización del mensaje (el proceso por el cual un cliente una creencia de la marca como propia).

\section{Búsqueda de sitios web de empresas}

La búsqueda de empresas dedicadas a los regalos de empresa navideños podría verse afectada por la estacionalidad propia del negocio, sobre todo en cuanto a la promoción y publicidad en los propios sitios web. Por ello se prefirió ampliar la búsqueda a regalos de empresa en general, dentro del ámbito español. Los términos de búsqueda utilizados en Google han sido por tanto "regalos de empresa" (fecha de búsqueda: 11 de febrero de 2011).

Lista de los primeros 20 resultados (ordenados por relevancia):

- www.grupobillingham.com

- www.regalopublicidad.com

- www.regaloempresas.com

- www.delfinregalos.com

- www.todoregalos.es

- www.todoregalos.com

- www.technilogo.es

- www.promosbbt.com

- www.gadgetoregalo.com

- www.apeir.com

- www.novodistribuciones.com/regalos-de-empresa-c-90.html

- www.portalreclamos.com

- www.bnova.es

- www.regalosdeempresa.net

- www.regalosdeempresa.com 
- www.verdementa.es

- www.blisspublicidad.com

- www.regalosmerchandising.com

- www.korisimport.com

- www.empubli.com

Se descartó el conjunto de resultados bajo el epígrafe "direcciones de regalos de empresa próximas a Valencia” (proporcionado de manera automática por Google), ya que su ámbito geográfico es más restrictivo. Además, en la lista de dichos resultados prima el criterio geográfico sobre otros criterios de posicionamiento.

\section{Criterios de análisis}

A continuación se enumeran los criterios de análisis seleccionados para su aplicación en la lista previa de sitios web. En la selección se ha pretendido incluir criterios basados en las disciplinas de arquitectura de la información y usabilidad, junto con algunos propios del marketing en Internet. Por ello el grado de coincidencia con los criterios expuestos en el punto 2 (relativos a dicho marketing) no es total.

Entre paréntesis se indica el método de evaluación, en su mayoría consistente en la verificación de la existencia de un determinado elemento, función o propiedad. El texto subrayado en cada criterio ayuda en la identificación de cada criterio dentro del propio análisis.

1. Coherencia del texto de los resultados en Google con los términos de búsqueda: ¿aparece la expresión "regalos de empresa" dentro de cada resultado ofrecido? (sí/no).

2. Metadatos descriptivos en la cabecera (head) del código fuente en la página de inicio: etiqueta $<$ title $>$, metaetiquetas description y keywords. Búsqueda de otros términos adicionales a "regalos de empresa" (presencia/ausencia).

3. Identificación de la empresa: sección "quienes somos" o equivalente, microformato hcard ${ }^{3}$, CIF/NIF (presencia/ausencia).

4. Ubicación del negocio: dirección postal, mapa, microformato geo (presencia/ ausencia).

5. Aviso legal: sección informativa sobre la política de la empresa en cuanto a cuestiones legales, condiciones generales, protección de datos (presencia/ ausencia).

6. Objetivos de la empresa o de la web detallados en la página de inicio: ¿se indica claramente el objetivo? (sí /no).

7. ¿Se pone en práctica el branding?: el objetivo es que haya un reconocimiento de la marca. Está relacionado con las sensaciones, y se consigue mediante un diseño apropiado y la presencia de logotipos, anuncios, banners, etc. (sí /no).

8. URL de la página de inicio coherente: ¿su composición tiene contenido semántico y es mnemotécnica? (sí / no).

9. Estructuración de la organización del sitio: estructuración de las secciones de menús principales y secundarios, junto con la navegación resultante (adecuada/ 
inadecuada).

10. Estructuración de los contenidos: uso de encabezamientos y párrafos, redacción del contenido (adecuada/inadecuada).

11. Diseño gráfico. Está relacionado con el branding y puede aportar una sensación de disfrute al navegante. Debe además tener en cuenta su influencia en la usabilidad (adecuado o atractivo /inadecuado o no atractivo).

12. Ayuda al usuario: presencia de las secciones de preguntas frecuentes y guía para procesos de compra, existencia de un mapa web (si/no).

13. Retroalimentación: posibilidad de contactar con la empresa a través de correo electrónico, formularios, teléfonos o fax (sí / no).

14. ¿Existe una segmentación de la clientela? Para un negocio de artículos de regalo deberían identificarse y clasificarse los clientes potenciales, ofreciéndose un acceso propio a los contenidos y/o productos para cada segmento (sí /no).

15. ¿Se observan prácticas de marketing de guerrilla, marketing viral o experiencial? Para averiguarlo se analizan los 20 primeros resultados en Google (tanto por búsqueda en la web como en Videos y Noticias) que puedan ser relevantes por su contenido. El término de búsqueda es el nombre de la empresa (sí/no). Por otra parte, el marketing viral está relacionado con el marketing integrado (ver el siguiente punto), ya que puede utilizar a su favor redes de comunicación entre personas (incluyendo servicios de redes sociales) para aumentar su efectividad. Por ello, se analizan dichos servicios de redes sociales para comprobar prácticas de marketing viral (si/no).

16. ¿Utiliza campañas de marketing integrado?: también llamado social media marketing, el marketing integrado forma parte del marketing en Internet y éste a su vez del marketing digital. Para evaluarlo se ha comprobado la existencia de perfiles en los servicios de blogs, Facebook, Flickr, YouTube, y Twitter (sí/no).

17. Coherencia de los productos en venta respecto de la búsqueda en Google: ¿se incluyen efectivamente entre los productos ofertados artículos de regalo para empresas? (sí/no).

18. Importancia de los productos en venta dentro de la estructuración del contenido. ¿Destacan por su ubicación y presentación? (si/no).

19. Compra online: ¿es posible realizar el proceso de compra a través del sitio web?: presupuesto, pedido en firme, pago, seguimiento de pedido (posible/no posible).

20. Servicios de valor añadido. Se enumeran los servicios presentes: carrito de la compra, sistemas de verificación de la seguridad del sitio, etc.

\section{Análisis de los sitios web}

La disponibilidad de información y datos para realizar un análisis DAFO en sentido formal es muy limitada. Habría que realizar un análisis exhaustivo del entorno de la empresa sobre los grupos de interés, la legislación, demografía, política y tecnología. En el análisis interno de la propia empresa se estudiarían factores como la disponibilidad de capital, los recursos financieros, el personal, la calidad de los productos o la propia organización.

En su lugar se han analizado los sitios web de las empresas según los criterios 
expuestos, considerándolos como parte del análisis interno. Los resultados positivos se han encuadrado dentro de las fortalezas, y los negativos dentro de las debilidades. Para determinar las oportunidades y amenazas se ha tenido en cuenta el conjunto de los 20 sitios web, analizados como entorno contra el que se contrasta un caso determinado.

Por otra parte, no se ha utilizado una matriz DAFO para realizar el análisis. En su lugar se ha usado un modelo simplificado en el que cada registro representa a un sitio web y los campos contienen por separado la síntesis del análisis de las fortalezas, debilidades, oportunidades y amenazas.

La tabla con los resultados del análisis se muestra, dadas sus dimensiones, en el anexo I.

\section{Discusión de resultados y conclusiones}

Todas los sitios web consiguen una coherencia entre los términos de búsqueda en Google ("regalos de empresa") y el texto que les representa dentro de los resultados (incluido el título, el fragmento descriptivo y la URL de la página web). Aunque la mayoría incluye metadatos descriptivos, éstos suelen ser mejorables tanto en la calidad del contenido como en el número de campos que podrían ser útiles (autor, descripción, lenguaje, etc.).

En general, las amenazas existentes para las empresas analizadas se centran en empresas más competentes en el ámbito online, que publiquen sitios web cuya arquitectura, diseño gráfico y servicios añadidos estén más en consonancia con la Internet actual. En la mayoría de casos estudiados, la arquitectura y diseño remiten a versiones de la Web ya superadas.

Otra seria amenaza es la incapacidad de distinguir desde un primer momento a unas empresas de otras. Esto es debido a la existencia de URLS poco diferenciales, y a la falta de desarrollo del branding, de la arquitectura del sitio y de la originalidad del diseño gráfico. Hay excepciones llamativas como el sitio web de Verdementa.

Por lo dicho, las oportunidades tienen las mismas bases que las amenazas: hay un amplio margen para destacar entre la competencia si se mejora la arquitectura del sitio web, el diseño gráfico, la estructuración de contenidos (incluida la calidad de redacción), la imagen de empresa, etc. Una funcionalidad con implantación escasa es la posibilidad de comentar los productos en venta, lo que puede atraer a más usuarios si se logra un uso efectivo. Análogamente, con la sindicación de los contenidos se puede aumentar la frecuencia de las visitas.

Otro punto a mejorar en todos los casos es la segmentación de la clientela. No hay ninguna web analizada que ofrezca a sus clientes, desde un primer momento, el acceso a los productos a través de la identificación con un tipo de usuario. Por ejemplo, podría accederse a través de enlaces que pregunten: ¿eres fumador? ¿Te preocupa el medio ambiente?, etc. 
Llama la atención cómo se recurre en general a la venta mediante la petición por parte del cliente de un presupuesto previo. Dado el volumen de unidades que se suelen vender en este tipo de negocio, es comprensible. Sin embargo, un proceso de compra online más ágil y completo constituiría sin duda una ventaja frente a otros competidores: p. ej., ofreciendo una información del stock permanentemente actualizada para poder confirmar en el acto la existencia de las unidades a comprar; o incluir servicios como el pago, el envío y el seguimiento de productos a través del propio sitio web.

Por otra parte, ninguna sitio web analizado aplica microformatos. Es otra oportunidad para ofrecer servicios de valor añadido, sobretodo de cara a las plataformas móviles: hcards descargables, microformato geo con la ubicación del negocio, etc.

Finalmente, no hay ningún sitio web que se haya atrevido a realizar marketing viral, experiencial o de guerrilla. Los vídeos que ofrecen a través de YouTube dejan un regusto a anuncio de canal televisivo comercial muy poco seductor o creíble (como por ejemplo en el caso de Novodistribuciones $\left.{ }^{4}\right)$. Hay un amplio espacio para la creatividad e innovación.

En conclusión, el estudio del análisis muestra un retraso generalizado respecto a las posibilidades actuales de un sitio web de carácter comercial. Existe un margen de mejora que puede ser aprovechado como oportunidad por las empresas del sector, tanto por las que ya poseen una tienda online y quieran afianzarse como por aquellas que se incorporen y pretendan destacar por encima de la competencia. Para ello es recomendable la asistencia de profesionales con competencias en disciplinas relevantes como la arquitectura de la información y el marketing online.

\section{Reconocimientos}

Agradecimientos a José Antonio Martínez por animarme a presentar el artículo y por la ayuda, a Jorge Serrano por los consejos y la inspiración y a Elena Benesiu por todo el apoyo y la revisión del texto.

\section{Notas}

1. Como se explica en el punto 3. Búsqueda de sitios web de empresas, el alcance de la investigación se amplió a los regalos de empresa, en sentido general.

2. En sentido general, no confundir con los servicios de redes sociales propiamente dichos, como p. ej. Facebook.

3. Para analizar la presencia de todos los microformatos se ha utilizado la extensión Operator del navegador Firefox. URL: https://addons.mozilla.org/es-ES/firefox/addon/operator/ (fecha de consulta: 02/09/2011).

4. Véase http://www.youtube.com/user/novodistribuciones\#p/a/u/o/9uCxCwtXKno (fecha de consulta: 10/09/2011).

5. Véase http://www.ivalio.com/list/O2fb9083be78b7d21664dd978fcdbb99/bliss-publicidad,-1timo (fecha de consulta: 24/08/2011). 


\section{Referencias}

BURKE, R.R. (2002). "Technology and the Customer Interface: What Consumers Want in the Physical and Virtual Store”. Journal of the Academy of Marketing Science, vol. 30 no. 4 pp. 41 1-432. ISSN 0092-0703.

DHOLAKIA, RUBY ROY y ZHAO, MIAO (2010). "Effects of online store attributes on customer satisfaction and repurchase intentions". International Journal of Retail \& Distribution Management, vol. 38 no. 7 pp. 482 - 496. ISSN 0959-0552.

DREZE, X. y ZUFRYDEN, F. (2004). "Measurement of online visibility and its impact on Internet traffic”. Journal of Interactive Marketing, vol. 18 no. 1 pp.pp. 20-37. ISSN 1094-9968.

GOOGLE. Guía para principiantes sobre optimización para motores de búsqueda. Disponible en: http://www.google.es/webmasters/docs/guia_optimizacion_motores_busqueda.pdf (consultado en 02/09/2011).

KALYANAM, K. y MCINTYRE, S., MASONIS, J. T. (2007). “Adaptive experimentation in interactive marketing: The case of viral marketing at Plaxo". Journal of Interactive Marketing, vol. 21 no. 3 pp. 72-85. ISSN 1094-9968.

LESKOVEC, J., ADAMIC, L.A. y HUBERMAN, B.A. (2007). "The Dynamics of Viral Marketing". ACM Transactions on the Web, Vol. 1 no. 1. Disponible en: http://dl.acm.org/citation.cfm? id=1232727 (consultado en 02/09/2011). ISSN: 1559-1131 EISSN: 1559-114X.

LII, Y.-S., LIM, H. J. y TSENG, L.P. D. (2004). “The effects of Web operational factors on marketing performance”. Journal of American Academy of Business, vol. 5 no. 1/2 pp. 486-494. ISSN 1540-1200.

MARGOLIS, J. y GARRIGAN, P. Guerrilla Marketing For Dummies. Hoboken, NJ, USA: Wiley, 2008. ISBN 978-0-470-28967-9.

MORVILLE, P. y ROSENFELD, L. Information Architecture for the World Wide Web. Sebastopol, Calif.:O'Reilly, 2006. ISBN 978-0-596-52734-1.

SMILANSKY, S. Experiential Marketing : A Practical Guide to Interactive Brand Experiences. London: Kogan Page, 2009. ISBN 978-0-7494-5275-9.

TUTEN, T.L. Advertising 2.0: social media marketing in a Web 2.0 world. Westport, CT, USA: Praeger, 2008. ISBN 978-0-313-35296-6.

WEATHERS, D. y MAKIENKO, I. (2006). “Assessing the relationships between e-tail success and product and Web site factors". Journal of Interactive Marketing, vol. 20 no. 2 pp. 41-54. ISSN 10949968.

WILSON, R. F. (2000).”The Six Simple Principles of Viral Marketing”. Web Marketing Today. Disponible en:

http://www.wilsonweb.com/wmt5/viral-principles.htm (consultado en 27/08/2011). ISSN 10948112 .

YOON, S.-J (2002). "The antecedents and consequences of trust in online-purchase decisions". Journal of Interactive Marketing, vol. 16 no. 2 pp. 47-63. ISSN 1094-9968. 


\section{ANEXO I. RESULTADOS DEL ANÁLISIS DE LA MUESTRA}

\section{Grupo Billingham}

\begin{tabular}{|c|c|c|c|}
\hline Fortalezas & Debilidades & Oportunidades & Amenazas \\
\hline $\begin{array}{l}\text { Coherencia del texto en Goo- } \\
\text { gle. } \\
\text { Metadatos descriptivos, me- } \\
\text { jorables. } \\
\text { Identificación de la empresa, } \\
\text { mejorable. } \\
\text { Ubicación y mapa. } \\
\text { Aviso legal. } \\
\text { Objetivos detallados. } \\
\text { URL coherente. } \\
\text { Estructuración de los conte- } \\
\text { nidos, mejorable. } \\
\text { Diseño gráfico, mejorable. } \\
\text { Ayuda al usuario. } \\
\text { Retroalimentación. } \\
\text { Productos coherentes. Im- } \\
\text { portancia de productos. } \\
\text { Compra on line. } \\
\text { Servicios de valor añadido: } \\
\text { carrito de compra; VeriSign. }\end{array}$ & $\begin{array}{l}\text { Ausencia de micro- } \\
\text { formatos. } \\
\text { Branding. } \\
\text { Estructuración de la } \\
\text { organización. } \\
\text { Ausencia de marke- } \\
\text { ting viral/guerrilla/ } \\
\text { experiencial. } \\
\text { Marketing integra- } \\
\text { do: solo un blog in- } \\
\text { accesible. } \\
\text { Segmentación de la } \\
\text { clientela solo a } \\
\text { través de regalos } \\
\text { ecológicos. }\end{array}$ & $\begin{array}{l}\text { Fidelización de clien- } \\
\text { tes gracias a: } \\
\text { Los servicios de va- } \\
\text { lor añadido. } \\
\text { La sensación de con- } \\
\text { fianza producida por } \\
\text { la información sobre } \\
\text { la empresa, la retroa- } \\
\text { limentación y el ser- } \\
\text { vicio VeriSign. }\end{array}$ & $\begin{array}{l}\text { Empresas que } \\
\text { hayan desarro- } \\
\text { llado mejor su } \\
\text { branding y mar- } \\
\text { keting: p.ej. Ver- } \\
\text { dementa, Tech- } \\
\text { nilogo, etc. }\end{array}$ \\
\hline
\end{tabular}

\section{Regalo Publicidad}

\begin{tabular}{|c|c|c|c|}
\hline Fortalezas & Debilidades & Oportunidades & Amenazas \\
\hline $\begin{array}{l}\text { Coherencia del texto en Goo- } \\
\text { gle. } \\
\text { Identificación de la empresa, } \\
\text { mejorable. } \\
\text { Ubicación. } \\
\text { Aviso legal. } \\
\text { Objetivos detallados. } \\
\text { URL coherente pero poco } \\
\text { diferencial. } \\
\text { Ayuda al usuario, mejorable } \\
\text { (sobretodo en el proceso de } \\
\text { pedidos). } \\
\text { Retroalimentación, mejora- } \\
\text { ble. } \\
\text { Marketing integrado (blog, } \\
\text { Facebook, Twitter). } \\
\text { Productos coherentes. Im- } \\
\text { portancia de productos. }\end{array}$ & $\begin{array}{l}\text { Ausencia de metada- } \\
\text { tos descriptivos y de } \\
\text { microformatos. } \\
\text { Branding. } \\
\text { Estructuración de la } \\
\text { organización. } \\
\text { Estructuración de los } \\
\text { contenidos. } \\
\text { Diseño gráfico. } \\
\text { Segmentación de } \\
\text { clientela. } \\
\text { Prácticas de marke- } \\
\text { ting. } \\
\text { Compra on line. } \\
\text { Ausencia de marke- } \\
\text { ting viral/guerrilla/ } \\
\text { experiencial. } \\
\text { Ausencia de servicios } \\
\text { de valor añadido. }\end{array}$ & $\begin{array}{l}\text { Mayor cuota poten- } \\
\text { cial de mercado gra- } \\
\text { cias a la visibilidad } \\
\text { que le proporciona el } \\
\text { marketing integrado. }\end{array}$ & $\begin{array}{l}\text { Puede pasar } \\
\text { desapercibida } \\
\text { entre los resulta- } \\
\text { dos de Google, o } \\
\text { incluso confun- } \\
\text { dirse con otra } \\
\text { empresa. Esto, } \\
\text { sumado a la falta } \\
\text { de compra on } \\
\text { line y a la defi- } \\
\text { ciencia de bran- } \\
\text { ding, puede lle- } \\
\text { var a un rápido } \\
\text { descarte por } \\
\text { parte de los } \\
\text { usuarios. }\end{array}$ \\
\hline
\end{tabular}




\begin{tabular}{|c|c|c|c|}
\hline \multicolumn{4}{|l|}{ 3. Regalo-empresas España } \\
\hline Fortalezas & Debilidades & Oportunidades & Amenazas \\
\hline $\begin{array}{l}\text { Coherencia del texto en Goo- } \\
\text { gle. } \\
\text { Metadatos descriptivos, me- } \\
\text { jorables. } \\
\text { Identificación de empresa, } \\
\text { mejorable. } \\
\text { Ubicación. } \\
\text { Aviso legal. } \\
\text { Objetivos detallados. } \\
\text { URL coherente pero poco } \\
\text { diferencial. } \\
\text { Estructuración de los conte- } \\
\text { nidos, mejorable. } \\
\text { Diseño gráfico, mejorable. } \\
\text { Ayuda al usuario. } \\
\text { Retroalimentación. } \\
\text { Segmentación de la clientela: } \\
\text { bolsas de congresos, artículos } \\
\text { deportivos. Mejorable. } \\
\text { Productos coherentes. Im- } \\
\text { portancia de los productos. } \\
\text { Servicios de valor añadido: } \\
\text { garantía de calidad respalda- } \\
\text { da por asociaciones. }\end{array}$ & $\begin{array}{l}\text { Ausencia de micro- } \\
\text { formatos. } \\
\text { Branding. } \\
\text { Estructuración de la } \\
\text { organización. } \\
\text { Ausencia de marke- } \\
\text { ting viral/guerrilla/ } \\
\text { experiencial. } \\
\text { Ausencia de marke- } \\
\text { ting integrado. } \\
\text { Compra on line. }\end{array}$ & $\begin{array}{l}\text { Fidelización de clien- } \\
\text { tes gracias a: } \\
\text { La ayuda ofrecida. } \\
\text { La sensación de con- } \\
\text { fianza producida por } \\
\text { la información sobre } \\
\text { la empresa, la retroa- } \\
\text { limentación y la ga- } \\
\text { rantía de calidad res- } \\
\text { paldada. }\end{array}$ & $\begin{array}{l}\text { Competencia } \\
\text { que ofrezca la } \\
\text { opción de com- } \\
\text { pra on line. }\end{array}$ \\
\hline \multicolumn{4}{|l|}{ 4. Delfin Regalos de Empresa } \\
\hline Fortalezas & Debilidades & Oportunidades & Amenazas \\
\hline $\begin{array}{l}\text { Coherencia del texto en Goo- } \\
\text { gle. } \\
\text { Metadatos descriptivos, mejo- } \\
\text { rables. } \\
\text { Identificación de la empresa. } \\
\text { Ubicación y mapa } \\
\text { Aviso legal, escindido en las } \\
\text { secciones Protección de datos } \\
\text { y Condiciones generales. } \\
\text { Objetivos detallados. } \\
\text { Branding. } \\
\text { Estructuración de la organi- } \\
\text { zación. } \\
\text { Estructuración de los conte- } \\
\text { nidos. } \\
\text { Diseño gráfico. } \\
\text { Retroalimentación. } \\
\text { Segmentación de la clientela a } \\
\text { través de las secciones Ecoló- } \\
\text { gicos, Fumador, Infantil. Me- } \\
\text { jorable. } \\
\text { Productos coherentes. Impor- } \\
\text { tancia de productos. } \\
\text { Servicios de valor añadido: } \\
\text { modalidades del buscador, } \\
\text { cuentas de usuario. }\end{array}$ & $\begin{array}{l}\text { Ausencia de micro- } \\
\text { formatos. } \\
\text { URL incoherente: } \\
\text { redirige a un domi- } \\
\text { nio .net. } \\
\text { Ayuda al usuario: la } \\
\text { sección de pregun- } \\
\text { tas frecuentes y la } \\
\text { guía de compra } \\
\text { están escondidas } \\
\text { dentro de la sección } \\
\text { Condiciones genera- } \\
\text { les. } \\
\text { Ausencia de marke- } \\
\text { ting viral/guerrilla/ } \\
\text { experiencial. } \\
\text { Ausencia de marke- } \\
\text { ting integrado. } \\
\text { Compra on line. }\end{array}$ & $\begin{array}{l}\text { Fidelización de clien- } \\
\text { tes gracias a: } \\
\text { La información sobre } \\
\text { la empresa y su ima- } \\
\text { gen de marca. } \\
\text { La comodidad para } \\
\text { navegar y buscar } \\
\text { unida al diseño gráfi- } \\
\text { co. } \\
\text { El trato personal a } \\
\text { través de cuentas de } \\
\text { usuario. }\end{array}$ & $\begin{array}{l}\text { Empresas más } \\
\text { innovadoras a } \\
\text { través de técni- } \\
\text { cas de marke- } \\
\text { ting o de servi- } \\
\text { cios on line (p. } \\
\text { ej. compra o } \\
\text { ayuda). }\end{array}$ \\
\hline
\end{tabular}


MEI, II, Vol. 3, nº 4, pág. 27

\begin{tabular}{|c|c|c|c|}
\hline \multicolumn{4}{|l|}{ 5. Todo regalos.es } \\
\hline Fortalezas & Debilidades & Oportunidades & Amenazas \\
\hline $\begin{array}{l}\text { Coherencia del texto en } \\
\text { Google. } \\
\text { Metadatos descriptivos, } \\
\text { mejorables. } \\
\text { Identificación de la empre- } \\
\text { sa, mejorable. } \\
\text { Ubicación. } \\
\text { URL coherente pero poco } \\
\text { diferencial. } \\
\text { Retroalimentación. }\end{array}$ & $\begin{array}{l}\text { Ausencia de de microfor- } \\
\text { matos. } \\
\text { Aviso legal. } \\
\text { Objetivos no detallados. } \\
\text { Branding. } \\
\text { Estructuración de la or- } \\
\text { ganización. } \\
\text { Estructuración de los } \\
\text { contenidos. } \\
\text { Diseño gráfico muy mejo- } \\
\text { rable. } \\
\text { Ayuda al usuario. } \\
\text { Segmentación de la clien- } \\
\text { tela. } \\
\text { Ausencia de marketing } \\
\text { viral/guerrilla/ } \\
\text { experiencial. } \\
\text { Ausencia de marketing } \\
\text { integrado. } \\
\text { Coherencia e importancia } \\
\text { de los productos. } \\
\text { Compra on line. } \\
\text { Ausencia de servicios de } \\
\text { valor añadido. }\end{array}$ & $\begin{array}{l}\text { Empresas que } \\
\text { ofrezcan mejorar } \\
\text { el diseño del sitio } \\
\text { web y los servi- } \\
\text { cios ofrecidos a los } \\
\text { clientes. }\end{array}$ & $\begin{array}{l}\text { Cualquier em- } \\
\text { presa de la com- } \\
\text { petencia puede } \\
\text { ofrecer mejor } \\
\text { imagen y servi- } \\
\text { cio a través de } \\
\text { un sitio web. }\end{array}$ \\
\hline
\end{tabular}


MEI, II, Vol. 3, nº 4, pág. 28

\section{Todo regalos.com}

\begin{tabular}{|c|c|c|c|}
\hline Fortalezas & Debilidades & Oportunidades & Amenazas \\
\hline $\begin{array}{l}\text { Coherencia del texto en } \\
\text { Google. } \\
\text { Objetivos detallados. } \\
\text { URL coherente pero poco } \\
\text { diferencial. } \\
\text { Retroalimentación. } \\
\text { Segmentación de la clientela } \\
\text { según la clase de producto: } \\
\text { regalo de empresa, regalo } \\
\text { promocional, regalo publici- } \\
\text { tario. } \\
\text { Coherencia de los productos. }\end{array}$ & $\begin{array}{l}\text { Ausencia de microforma- } \\
\text { tos. } \\
\text { Metadatos descriptivos } \\
\text { incompletos. } \\
\text { Identificación de la em- } \\
\text { presa. } \\
\text { Ubicación. } \\
\text { Aviso legal. } \\
\text { Branding. } \\
\text { Estructuración de la } \\
\text { organización: categorías, } \\
\text { enlaces internos rotos. } \\
\text { Estructuración de conte- } \\
\text { nidos. } \\
\text { Diseño gráfico: la ma- } \\
\text { yoría de imágenes no se } \\
\text { cargan. } \\
\text { Ayuda al usuario. } \\
\text { Ausencia de marketing } \\
\text { viral/guerrilla/ } \\
\text { experiencial. } \\
\text { Ausencia de marketing } \\
\text { integrado. } \\
\text { Importancia de los pro- } \\
\text { ductos, ya que no se pue- } \\
\text { de acceder a su informa- } \\
\text { ción completa. } \\
\text { Compra on line. } \\
\text { Ausencia de servicios de } \\
\text { valor añadido. }\end{array}$ & $\begin{array}{l}\text { Sitio web pertene- } \\
\text { ciente a la misma } \\
\text { empresa que en el } \\
\text { caso anterior, con } \\
\text { resultados prácti- } \\
\text { camente idénticos. }\end{array}$ & $\begin{array}{l}\text { Sitio web perte- } \\
\text { neciente a la } \\
\text { misma empresa } \\
\text { que en el caso } \\
\text { anterior, con } \\
\text { resultados } \\
\text { prácticamente } \\
\text { idénticos. }\end{array}$ \\
\hline
\end{tabular}




\section{Technilogo España}

\begin{tabular}{|c|c|c|c|}
\hline Fortalezas & Debilidades & Oportunidades & Amenazas \\
\hline $\begin{array}{l}\text { Coherencia del texto en Goo- } \\
\text { gle. } \\
\text { Metadatos descriptivos. } \\
\text { Identificación de la empresa, } \\
\text { mejorable. } \\
\text { Ubicación. } \\
\text { Objetivos detallados. } \\
\text { Branding. } \\
\text { URL coherente. } \\
\text { Estructuración de la organiza- } \\
\text { ción, mejorable. } \\
\text { Estructuración de los conteni- } \\
\text { dos, mejorable. } \\
\text { Diseño gráfico. } \\
\text { Retroalimentación } \\
\text { Marketing integrado: YouTu- } \\
\text { be; Facebook y LinkedIn } \\
\text { (ambos para Technilogo Ar- } \\
\text { gentina). } \\
\text { Coherencia de los productos. } \\
\text { Importancia de los productos. } \\
\text { Compra on line (petición de } \\
\text { presupuesto). } \\
\text { Servicios de valor añadido: } \\
\text { carrito de la compra; posibili- } \\
\text { dad de exportar información } \\
\text { de los productos a redes y } \\
\text { marcadores sociales. }\end{array}$ & $\begin{array}{l}\text { Ausencia de micro- } \\
\text { formatos. } \\
\text { Aviso legal. } \\
\text { Ayuda al usuario: } \\
\text { falta una sección de } \\
\text { preguntas frecuen- } \\
\text { tes, el mapa web no } \\
\text { es accesible. } \\
\text { Segmentación de la } \\
\text { clientela. } \\
\text { Ausencia de marke- } \\
\text { ting viral/guerrilla/ } \\
\text { experiencial. }\end{array}$ & $\begin{array}{l}\text { Posibilidad de domi- } \\
\text { nio sobre la mayoría } \\
\text { de competidores del } \\
\text { análisis, gracias a: } \\
\text { La identificación e } \\
\text { imagen de la empre- } \\
\text { sa. } \\
\text { La arquitectura de } \\
\text { información y el dise- } \\
\text { ño del sitio. } \\
\text { El posicionamiento } \\
\text { por metadatos. } \\
\text { Las opciones de com- } \\
\text { pra. } \\
\text { La presencia de sus } \\
\text { artículos en redes } \\
\text { sociales. }\end{array}$ & $\begin{array}{l}\text { Desconfianza } \\
\text { por parte del } \\
\text { cliente poten- } \\
\text { cial al faltar } \\
\text { las secciones } \\
\text { de aviso legal } \\
\text { y preguntas } \\
\text { frecuentes. }\end{array}$ \\
\hline
\end{tabular}


MEI, II, Vol. 3, n 4, pág. 30

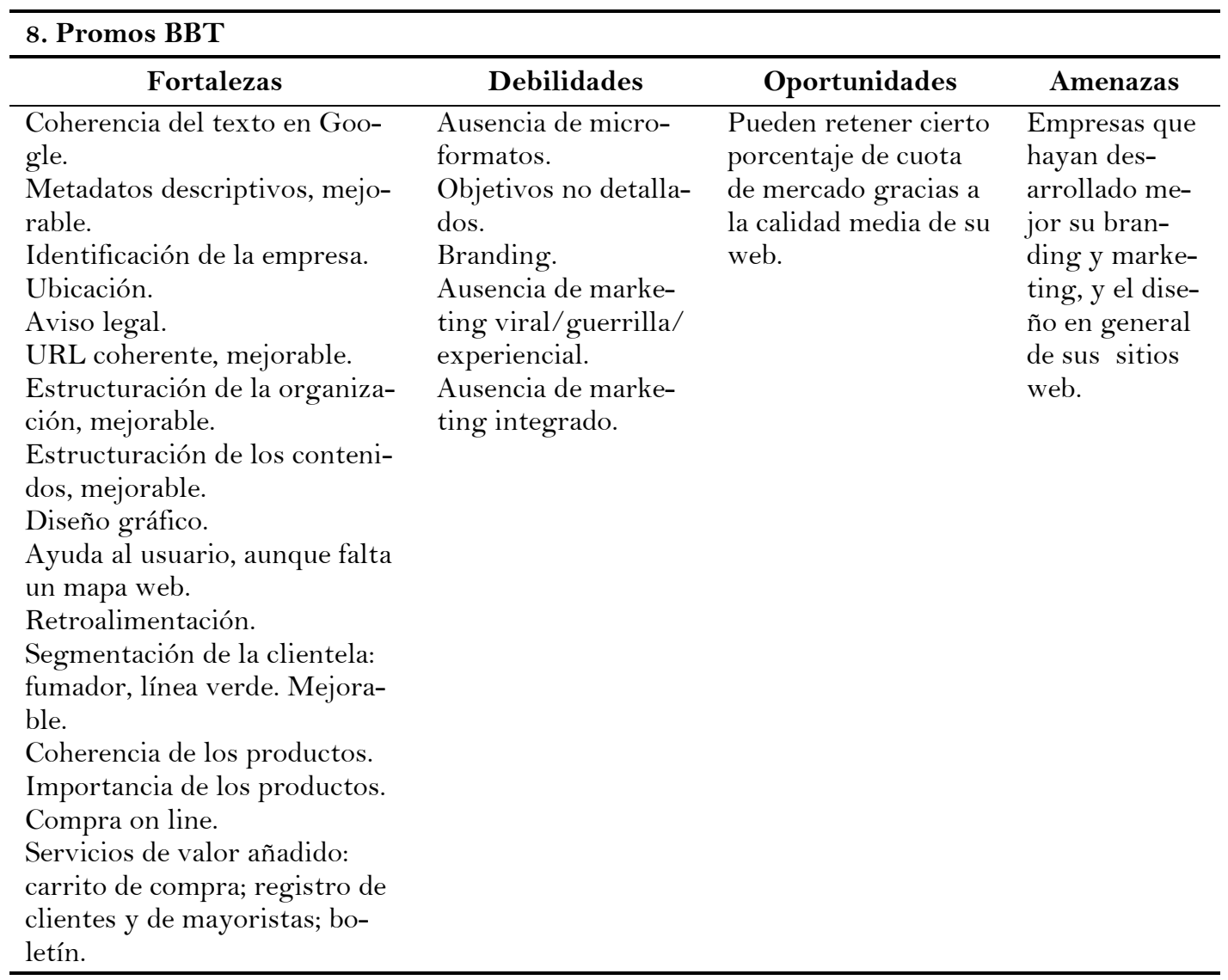


MEI, II, Vol. 3, n 4, pág. 31

\begin{tabular}{|c|c|c|c|}
\hline \multicolumn{4}{|l|}{ 9. Gadget o regalo } \\
\hline Fortalezas & Debilidades & Oportunidades & Amenazas \\
\hline $\begin{array}{l}\text { Coherencia del texto en } \\
\text { Google. } \\
\text { Metadatos descriptivos. } \\
\text { Ubicación. } \\
\text { Aviso legal, mejorable. } \\
\text { Objetivos detallados. } \\
\text { Branding, mejorable. } \\
\text { URL coherente. } \\
\text { Estructuración de la organi- } \\
\text { zación. } \\
\text { Estructuración de los conte- } \\
\text { nidos, mejorable. } \\
\text { Diseño gráfico. } \\
\text { Retroalimentación. } \\
\text { Marketing integrado: You- } \\
\text { Tube, Facebook, Twitter, } \\
\text { Picasa. } \\
\text { Coherencia de los produc- } \\
\text { tos. Importancia de los pro- } \\
\text { ductos. } \\
\text { Compra on line (petición de } \\
\text { presupuesto). } \\
\text { Servicios de valor añadido: } \\
\text { opciones del buscador, certi- } \\
\text { ficado GoDaddy. }\end{array}$ & $\begin{array}{l}\text { Ausencia de micro- } \\
\text { formatos. } \\
\text { Identificación de la } \\
\text { empresa. } \\
\text { Ayuda al usuario. } \\
\text { Segmentación de la } \\
\text { clientela. } \\
\text { Ausencia de marke- } \\
\text { ting viral/guerrilla/ } \\
\text { experiencial. }\end{array}$ & $\begin{array}{l}\text { Puede atraer a nue- } \\
\text { vos clientes si poten- } \\
\text { cia sus redes sociales. } \\
\text { Puede ganar en posi- } \\
\text { cionamiento por los } \\
\text { metadatos. } \\
\text { Fidelización de los } \\
\text { clientes si mejora el } \\
\text { branding y la compra } \\
\text { on line. }\end{array}$ & $\begin{array}{l}\text { Desconfianza } \\
\text { del usuario por } \\
\text { falta de identifi- } \\
\text { cación de la em- } \\
\text { presa. } \\
\text { Abandono de } \\
\text { usuarios por } \\
\text { falta de ayuda. }\end{array}$ \\
\hline
\end{tabular}

\begin{tabular}{|c|c|c|c|}
\hline \multicolumn{4}{|l|}{ 10. Grupo Apeir } \\
\hline Fortalezas & Debilidades & Oportunidades & Amenazas \\
\hline $\begin{array}{l}\text { Coherencia del texto en } \\
\text { Google. } \\
\text { Metadatos descriptivos } \\
\text { Identificación de la empresa, } \\
\text { mejorable. } \\
\text { Ubicación. } \\
\text { Objetivos detallados. } \\
\text { URL coherente. } \\
\text { Estructuración de la organi- } \\
\text { zación, mejorable. } \\
\text { Estructuración de los conte- } \\
\text { nidos. } \\
\text { Diseño gráfico. } \\
\text { Retroalimentación. } \\
\text { Coherencia de los produc- } \\
\text { tos. Importancia de los pro- } \\
\text { ductos. } \\
\text { Compra on line (petición de } \\
\text { información/presupuesto). }\end{array}$ & $\begin{array}{l}\text { Ausencia de micro- } \\
\text { formatos útiles (solo } \\
\text { tag spaces que no } \\
\text { son operativos). } \\
\text { Aviso legal. } \\
\text { Branding. } \\
\text { Ayuda al usuario: } \\
\text { solo un mapa web. } \\
\text { Segmentación de la } \\
\text { clientela. } \\
\text { Ausencia de marke- } \\
\text { ting viral/guerrilla/ } \\
\text { experiencial. } \\
\text { Ausencia de marke- } \\
\text { ting integrado. } \\
\text { Ausencia de servi- } \\
\text { cios de valor añadi- } \\
\text { do. }\end{array}$ & $\begin{array}{l}\text { Puede mejorar la } \\
\text { satisfacción del usua- } \\
\text { rio si mejora la arqui- } \\
\text { tectura de informa- } \\
\text { ción del sitio y la } \\
\text { ayuda disponible. } \\
\text { Puede ganar en posi- } \\
\text { cionamiento por los } \\
\text { metadatos. }\end{array}$ & $\begin{array}{l}\text { Competencia } \\
\text { con una mayor } \\
\text { originalidad en } \\
\text { imagen de em- } \\
\text { presa, en marke- } \\
\text { ting y en servi- } \\
\text { cios añadidos. }\end{array}$ \\
\hline
\end{tabular}


MEI, II, Vol. 3, n 4, pág. 32

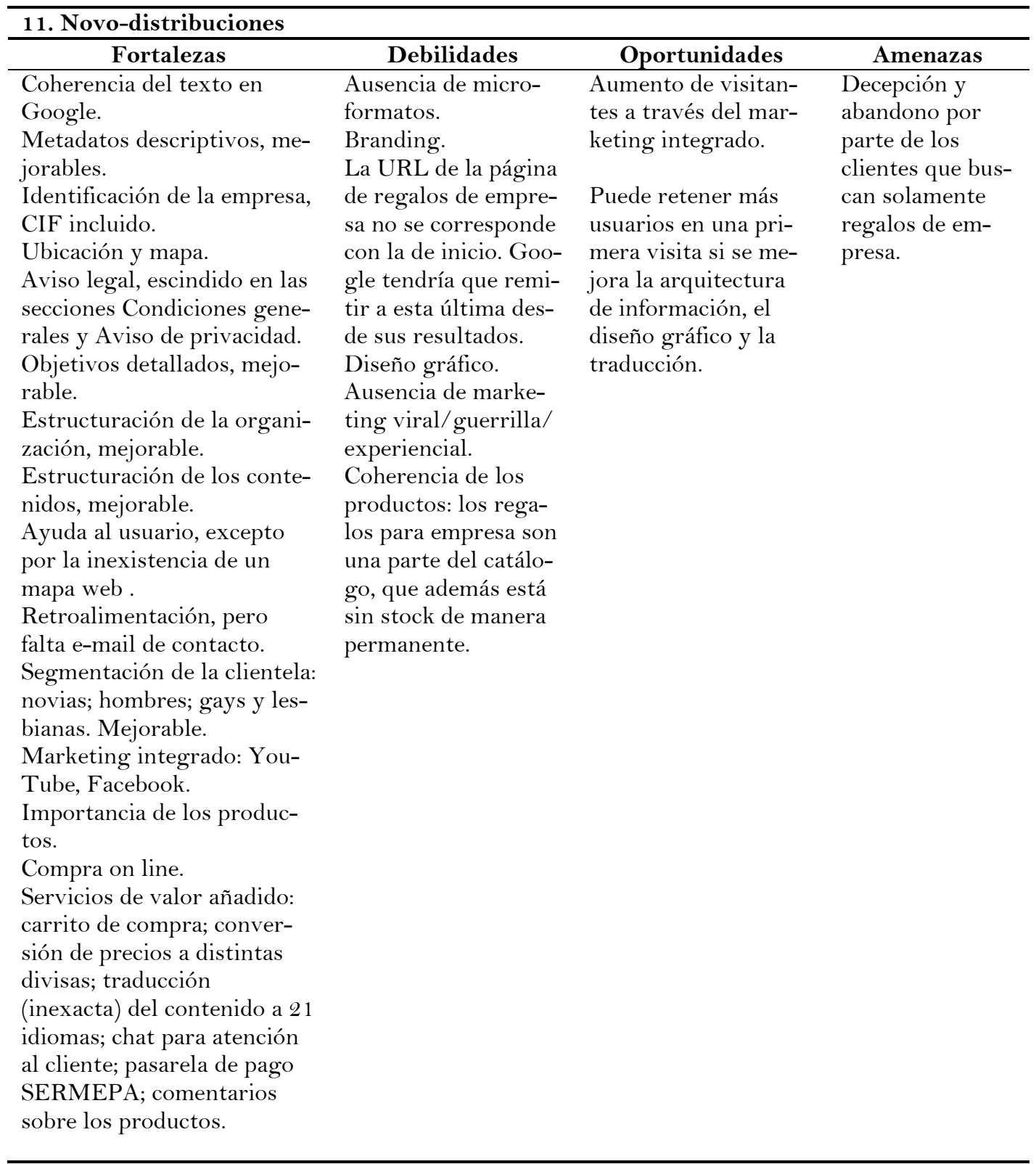


MEI, II, Vol. 3, n 4, pág. 33

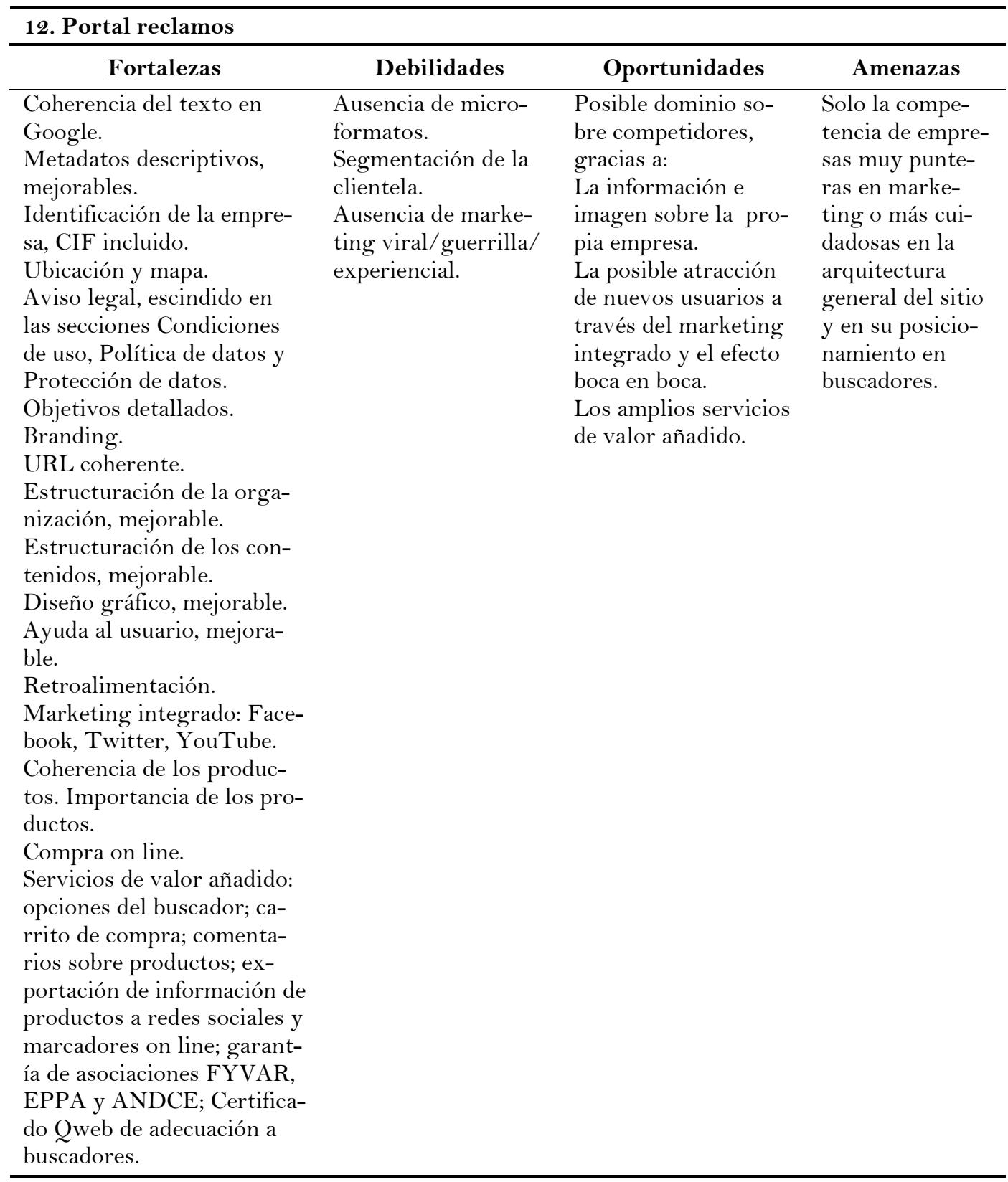




\section{Bieito nova}

\begin{tabular}{|c|c|c|c|}
\hline Fortalezas & Debilidades & Oportunidades & Amenazas \\
\hline $\begin{array}{l}\text { Coherencia del texto en } \\
\text { Google. } \\
\text { Metadatos descriptivos, } \\
\text { mejorables. } \\
\text { Identificación de la empresa, } \\
\text { mejorable. } \\
\text { Ubicación. } \\
\text { Objetivos detallados. } \\
\text { Branding. } \\
\text { URL coherente, mejorable. } \\
\text { Arquitectura del sitio. } \\
\text { Estructuración de los conte- } \\
\text { nidos. } \\
\text { Diseño gráfico. } \\
\text { Retroalimentación. } \\
\text { Coherencia e importancia de } \\
\text { los productos. } \\
\text { Servicios de valor añadido: } \\
\text { servidor FTP para envío de } \\
\text { ficheros; catálogos online. }\end{array}$ & $\begin{array}{l}\text { Ausencia de micro- } \\
\text { formatos. } \\
\text { Aviso legal no ope- } \\
\text { rativo. } \\
\text { Ayuda al usuario. } \\
\text { Segmentación de la } \\
\text { clientela. } \\
\text { Ausencia de marke- } \\
\text { ting viral/guerrilla/ } \\
\text { experiencial. } \\
\text { Ausencia de marke- } \\
\text { ting integrado. } \\
\text { Compra on line. }\end{array}$ & $\begin{array}{l}\text { Retención de visitan- } \\
\text { tes gracias al diseño } \\
\text { y la arquitectura, } \\
\text { siempre que incluya } \\
\text { un servicio de com- } \\
\text { pra on line. }\end{array}$ & $\begin{array}{l}\text { Competencia que } \\
\text { ejerce el marke- } \\
\text { ting integrado. }\end{array}$ \\
\hline
\end{tabular}

\section{Regalos de empresa.net}

\begin{tabular}{|c|c|c|c|}
\hline Fortalezas & Debilidades & Oportunidades & Amenazas \\
\hline $\begin{array}{l}\text { Coherencia del texto en } \\
\text { Google. } \\
\text { Metadatos descriptivos, } \\
\text { mejorables. } \\
\text { Identificación de la empresa, } \\
\text { mejorable. } \\
\text { Ubicación y mapa. } \\
\text { Aviso legal, mejorable. } \\
\text { URL coherente pero poco } \\
\text { diferencial. } \\
\text { Estructuración de la organi- } \\
\text { zación. } \\
\text { Estructuración de los conte- } \\
\text { nidos, mejorable. } \\
\text { Diseño gráfico. } \\
\text { Retroalimentación. }\end{array}$ & $\begin{array}{l}\text { Ausencia de micro- } \\
\text { formatos. } \\
\text { Ausencia de objeti- } \\
\text { vos detallados: no } \\
\text { informa de la ausen- } \\
\text { cia de un catálogo de } \\
\text { productos. } \\
\text { Branding. } \\
\text { Ayuda al usuario. } \\
\text { Segmentación de la } \\
\text { clientela. } \\
\text { Ausencia de marke- } \\
\text { ting viral/guerrilla/ } \\
\text { experiencial. } \\
\text { Ausencia de marke- } \\
\text { ting integrado. } \\
\text { Coherencia de pro- } \\
\text { ductos: no hay. } \\
\text { Importancia de pro- } \\
\text { ductos: no se ofer- } \\
\text { tan. } \\
\text { Compra online. }\end{array}$ & $\begin{array}{l}\text { Pocas oportunidades, } \\
\text { excepto la reconside- } \\
\text { ración de los objeti- } \\
\text { vos de la web y un } \\
\text { posterior rediseño. }\end{array}$ & $\begin{array}{l}\text { Abandono de } \\
\text { visitantes por } \\
\text { imposibilidad de } \\
\text { informarse sobre } \\
\text { los productos y } \\
\text { comprarlos. }\end{array}$ \\
\hline
\end{tabular}


15. Regalos de empresa.com

\begin{tabular}{|c|c|c|c|}
\hline Fortalezas & Debilidades & Oportunidades & Amenazas \\
\hline $\begin{array}{l}\text { Coherencia del texto en } \\
\text { Google. } \\
\text { Metadatos descriptivos, } \\
\text { mejorables. } \\
\text { Aviso legal. } \\
\text { Objetivos detallados: dar } \\
\text { información y consejos. } \\
\text { URL coherente pero poco } \\
\text { diferencial. } \\
\text { Estructuración de la organi- } \\
\text { zación. } \\
\text { Estructuración de los conte- } \\
\text { nidos, mejorable. } \\
\text { Ayuda al usuario. Falta ma- } \\
\text { pa web. } \\
\text { Retroalimentación. } \\
\text { Segmentación de la cliente- } \\
\text { la: dirigido específicamente } \\
\text { a usuarios con necesidades } \\
\text { de información sobre rega- } \\
\text { los de empresa. } \\
\text { Compra on line (petición de } \\
\text { presupuesto). }\end{array}$ & $\begin{array}{l}\text { Ausencia de micro- } \\
\text { formatos. } \\
\text { Identificación de la } \\
\text { empresa. } \\
\text { Ubicación. } \\
\text { Branding. } \\
\text { Diseño gráfico. } \\
\text { Ausencia de marke- } \\
\text { ting viral/guerrilla/ } \\
\text { experiencial. } \\
\text { Ausencia de marke- } \\
\text { ting integrado. }\end{array}$ & $\begin{array}{l}\text { Aumento de visitan- } \\
\text { tes si: } \\
\text { Mejoran el diseño } \\
\text { gráfico y la estructu- } \\
\text { ración de contenidos. } \\
\text { Los contenidos au- } \\
\text { mentan en profesio- } \\
\text { nalidad. } \\
\text { Realizan marketing } \\
\text { integrado y dotan de } \\
\text { imagen al proyecto. }\end{array}$ & $\begin{array}{l}\text { Viabilidad econó- } \\
\text { mica del proyec- } \\
\text { to: no se identifi- } \\
\text { ca la fuente de } \\
\text { ganancias. }\end{array}$ \\
\hline
\end{tabular}

\section{Verde menta}

\begin{tabular}{|c|c|c|c|}
\hline Fortalezas & Debilidades & Oportunidades & Amenazas \\
\hline $\begin{array}{l}\text { Coherencia del texto en } \\
\text { Google. } \\
\text { Metadatos descriptivos. } \\
\text { Objetivos detallados. } \\
\text { Branding. } \\
\text { URL coherente. } \\
\text { Estructuración de la organi- } \\
\text { zación. } \\
\text { Estructuración de los conte- } \\
\text { nidos. } \\
\text { Diseño gráfico. } \\
\text { Retroalimentación. } \\
\text { Coherencia de los productos. } \\
\text { Importancia de los produc- } \\
\text { tos. } \\
\text { Servicios de valor añadido: } \\
\text { RSS, Skype, certificado } \\
\text { Qweb de adecuación a busca- } \\
\text { dores. }\end{array}$ & $\begin{array}{l}\text { Ausencia de micro- } \\
\text { formatos. } \\
\text { Identificación de la } \\
\text { empresa: difícil de } \\
\text { localizar. } \\
\text { Ubicación: difícil de } \\
\text { localizar. } \\
\text { Aviso legal. } \\
\text { Ayuda al usuario: } \\
\text { solo mapa web. } \\
\text { Segmentación de la } \\
\text { clientela. } \\
\text { Ausencia de marke- } \\
\text { ting viral/guerrilla/ } \\
\text { experiencial. } \\
\text { Ausencia de marke- } \\
\text { ting integrado. } \\
\text { Compra on line. }\end{array}$ & $\begin{array}{l}\text { Retención y aumento } \\
\text { de usuarios gracias a } \\
\text { la arquitectura de } \\
\text { información y el dise- } \\
\text { ño. } \\
\text { Fidelización por las } \\
\text { opciones de retroali- } \\
\text { mentación. } \\
\text { Puede ganar en posi- } \\
\text { cionamiento por los } \\
\text { metadatos. }\end{array}$ & $\begin{array}{l}\text { Desconfianza } \\
\text { del cliente po- } \\
\text { tencial por falta } \\
\text { de información } \\
\text { sobre la empresa } \\
\text { y de avisos lega- } \\
\text { les. } \\
\text { Competencia de } \\
\text { empresas con } \\
\text { presencia en } \\
\text { redes sociales o } \\
\text { con servicios de } \\
\text { compra on line. }\end{array}$ \\
\hline
\end{tabular}


MEI, II, Vol. 3, nº 4, pág. 36

\begin{tabular}{|c|c|c|c|}
\hline Iblicidad & & & \\
\hline Fortalezas & Debilidades & Oportunidades & Amenazas \\
\hline $\begin{array}{l}\text { Coherencia del texto en Goo- } \\
\text { gle. } \\
\text { Metadatos descriptivos, me- } \\
\text { jorables. } \\
\text { Identificación de la empresa, } \\
\text { mejorable. } \\
\text { Ubicación. } \\
\text { Objetivos detallados. } \\
\text { URL coherente. } \\
\text { Estructuración de los conte- } \\
\text { nidos, mejorable. } \\
\text { Retroalimentación, mejora- } \\
\text { ble. } \\
\text { Segmentación de la clientela: } \\
\text { fumador, ropa laboral para } \\
\text { obreros. Mejorable. } \\
\text { Coherencia de los productos. } \\
\text { Importancia de los produc- } \\
\text { tos. } \\
\text { Compra on line. } \\
\text { Servicios de valor añadido: } \\
\text { cesta de compra; comentarios } \\
\text { sobre los productos. }\end{array}$ & $\begin{array}{l}\text { Ausencia de micro- } \\
\text { formatos. } \\
\text { Aviso legal. } \\
\text { Branding. } \\
\text { Estructuración de la } \\
\text { organización: nave- } \\
\text { gación. } \\
\text { Diseño gráfico. } \\
\text { Ayuda al usuario: } \\
\text { solo guía de compra. } \\
\text { Ausencia de marke- } \\
\text { ting viral/guerrilla/ } \\
\text { experiencial. } \\
\text { Ausencia de marke- } \\
\text { ting integrado. }\end{array}$ & $\begin{array}{l}\text { Aumento de confianza } \\
\text { de los usuarios si: } \\
\text { Se mejora la comuni- } \\
\text { cación con éstos. } \\
\text { Se mejora la informa- } \\
\text { ción sobre la empresa } \\
\text { y su política de com- } \\
\text { pras. }\end{array}$ & $\begin{array}{l}\text { Desorienta- } \\
\text { ción de los } \\
\text { usuarios por la } \\
\text { arquitectura } \\
\text { de información } \\
\text { del sitio y por } \\
\text { las ayudas } \\
\text { ofrecidas. }\end{array}$ \\
\hline
\end{tabular}

\begin{tabular}{|c|c|c|c|}
\hline \multicolumn{4}{|l|}{ 18. Regalos \& Merchadising } \\
\hline Fortalezas & Debilidades & Oportunidades & Amenazas \\
\hline $\begin{array}{l}\text { Coherencia del texto en } \\
\text { Google. } \\
\text { Metadatos descriptivos, me- } \\
\text { jorable. } \\
\text { Identificación de la empresa, } \\
\text { mejorable. } \\
\text { Aviso legal, mejorable. } \\
\text { Objetivos detallados. } \\
\text { URL coherente pero poco } \\
\text { diferencial. } \\
\text { Estructuración de la organi- } \\
\text { zación, mejorable. } \\
\text { Estructuración de los conte- } \\
\text { nidos. } \\
\text { Diseño gráfico, mejorable. } \\
\text { Retroalimentación, mejora- } \\
\text { ble. } \\
\text { Coherencia del os produc- } \\
\text { tos. Importancia de los pro- } \\
\text { ductos. } \\
\text { Compra on line: petición de } \\
\text { presupuesto y posterior pa- } \\
\text { go. } \\
\text { Servicios de valor añadido: } \\
\text { Pavpal. }\end{array}$ & $\begin{array}{l}\text { Ausencia de micro- } \\
\text { formatos. } \\
\text { Ubicación. } \\
\text { Branding. } \\
\text { Ayuda al usuario: } \\
\text { solo aparecen las con- } \\
\text { diciones de compra. } \\
\text { Segmentación de la } \\
\text { clientela. } \\
\text { Ausencia de marke- } \\
\text { ting viral/guerrilla/ } \\
\text { experiencial. } \\
\text { Ausencia de marke- } \\
\text { ting integrado. }\end{array}$ & $\begin{array}{l}\text { Pueden retener cierto } \\
\text { porcentaje de cuota de } \\
\text { mercado gracias a la } \\
\text { calidad media de su } \\
\text { web. }\end{array}$ & $\begin{array}{l}\text { Con la infor- } \\
\text { mación que no } \\
\text { aporta, no crea } \\
\text { confianza en el } \\
\text { usuario. } \\
\text { Competencia } \\
\text { de sitios web } \\
\text { con un mejor } \\
\text { diseño en ge- } \\
\text { neral, servicios } \\
\text { que las distin- } \\
\text { gan o proyec- } \\
\text { ción mediante } \\
\text { el marketing } \\
\text { integrado. }\end{array}$ \\
\hline
\end{tabular}


MEI, II, Vol. 3, nº 4, pág. 37

\begin{tabular}{|c|c|c|c|}
\hline \multicolumn{4}{|l|}{ 19. Koris Import } \\
\hline Fortalezas & Debilidades & Oportunidades & Amenazas \\
\hline $\begin{array}{l}\text { Coherencia del texto en Goo- } \\
\text { gle. } \\
\text { Metadatos descriptivos, mejo- } \\
\text { rable. } \\
\text { Identificación de la empresa, } \\
\text { mejorable. } \\
\text { Ubicación. } \\
\text { URL coherente. } \\
\text { Retroalimentación. } \\
\text { Coherencia de los productos. } \\
\text { Importancia de los productos. } \\
\text { Compra on line. }\end{array}$ & $\begin{array}{l}\text { Ausencia de micro- } \\
\text { formatos. } \\
\text { Aviso legal. } \\
\text { Objetivos no detalla- } \\
\text { dos. } \\
\text { Branding. } \\
\text { Estructuración de la } \\
\text { organización. } \\
\text { Estructuración de } \\
\text { los contenidos. } \\
\text { Diseño gráfico. } \\
\text { Ayuda al usuario. } \\
\text { Segmentación de la } \\
\text { clientela. } \\
\text { Ausencia de marke- } \\
\text { ting viral/guerrilla/ } \\
\text { experiencial. } \\
\text { Ausencia de marke- } \\
\text { ting integrado. } \\
\text { Servicios de valor } \\
\text { añadido. }\end{array}$ & $\begin{array}{l}\text { Mejora de la satisfac- } \\
\text { ción del cliente si } \\
\text { rediseñan la arquitec- } \\
\text { tura de información, } \\
\text { el diseño gráfico, etc. }\end{array}$ & $\begin{array}{l}\text { La imagen de } \\
\text { empresa poco } \\
\text { profesional } \\
\text { puede dismi- } \\
\text { nuir su compe- } \\
\text { titividad. }\end{array}$ \\
\hline
\end{tabular}

20. Empubli

\begin{tabular}{|c|c|c|c|}
\hline Fortalezas & Debilidades & Oportunidades & Amenazas \\
\hline $\begin{array}{l}\text { Coherencia del texto en Goo- } \\
\text { gle. } \\
\text { Metadatos descriptivos. } \\
\text { Ubicación, mapa. } \\
\text { Objetivos detallados. } \\
\text { URL coherente. } \\
\text { Estructuración de la organiza- } \\
\text { ción, mejorable. } \\
\text { Estructuración de los conteni- } \\
\text { dos, mejorable. } \\
\text { Diseño gráfico, mejorable en el } \\
\text { catálogo general. } \\
\text { Retroalimentación. } \\
\text { Segmentación de la clientela: } \\
\text { Oficina y negocios, Línea } \\
\text { ecológica, Mujer y cuidado } \\
\text { personal, Infantil. Mejorable. } \\
\text { Marketing integrado: Face- } \\
\text { book, Blogger,Twitter. } \\
\text { Coherencia de los productos. } \\
\text { Importancia de los productos, } \\
\text { mejorable. } \\
\text { Compra on line: petición de } \\
\text { presupuesto. } \\
\text { Servicios de valor añadido: } \\
\text { carrito de compra, mejorable. }\end{array}$ & $\begin{array}{l}\text { Ausencia de micro- } \\
\text { formatos. } \\
\text { Identificación de la } \\
\text { empresa. } \\
\text { Aviso legal. } \\
\text { Branding. } \\
\text { Ayuda al usuario. } \\
\text { Ausencia de marke- } \\
\text { ting viral/guerrilla/ } \\
\text { experiencial. }\end{array}$ & $\begin{array}{l}\text { Retención de los } \\
\text { clientes si se mejora } \\
\text { la arquitectura de } \\
\text { información y el dise- } \\
\text { ño gráfico. } \\
\text { Aumento de visitan- } \\
\text { tes si se gestionan } \\
\text { eficazmente los perfi- } \\
\text { les de la empresa en } \\
\text { las redes sociales. }\end{array}$ & $\begin{array}{l}\text { Competencia } \\
\text { con una mejor } \\
\text { imagen de } \\
\text { empresa y con } \\
\text { servicios de } \\
\text { valor añadidos. }\end{array}$ \\
\hline
\end{tabular}

